Supporting Information to

\title{
An Atomic Precision Graphene Model Compound for Bright Electrochemiluminescence and Organic Light-Emitting Diodes
}

Liuqing Yang ${ }^{1}$, Arthur D. Hendsbee ${ }^{2}$, Qin Xue ${ }^{3,4}$, Shuijian $\mathrm{He}^{1}$, Cindy R. De-Jager ${ }^{1}$, Guohua Xie ${ }^{3,4 *}$, Gregory C. Welch $^{2 *}$, Zhifeng Ding ${ }^{1 *}$

${ }^{1}$ Department of Chemistry, The University of Western Ontario, 1151 Richmond Street, London, ON N6A 5B7, Canada.

${ }^{2}$ Department of Chemistry, University of Calgary, 2500 University Drive N.W., Calgary, AB T2N 1N4, Canada.

${ }^{3}$ Sauvage Center for Molecular Sciences, Hubei Key Lab on Organic and Polymeric Optoelectronic Materials, Depart of Chemistry, Wuhan University, Wuhan 430072, China.

${ }^{4}$ Wuhan National Laboratory for Optoelectronics, Huazhong University of Science and Technology, Wuhan 430074, China.

Corresponding authors:

zfding@uwo.ca (ZD); gregory.welch@ucalgary.ca (GCW); guohua.xie@whu.edu.cn (GHX)

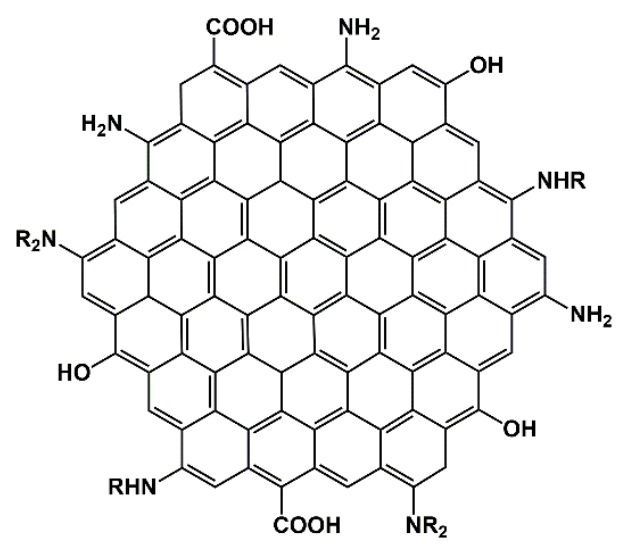

Scheme S1. Proposed structure of a random graphene quantum dot (GQD). 

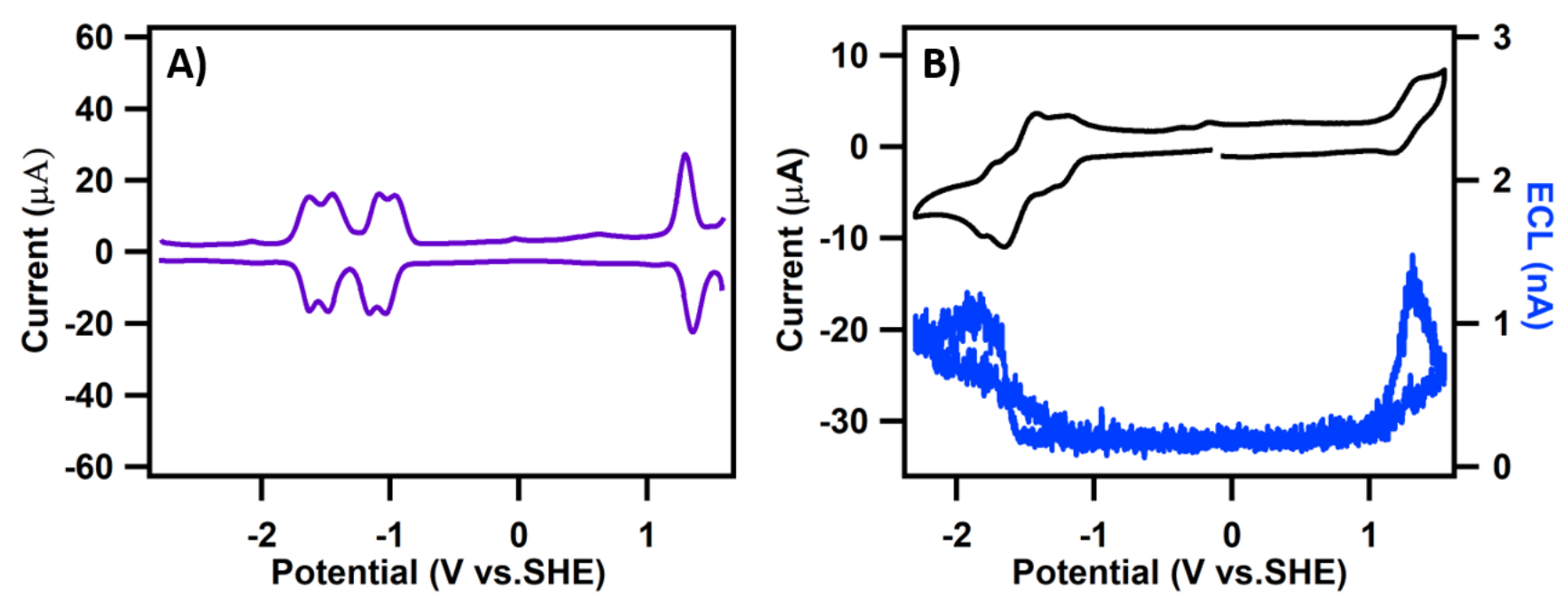

Figure S1. (A) Differential pulse voltammograms for $0.65 \mathrm{mM} \mathrm{tPDI}_{2} \mathrm{~N}-\mathrm{hex}$ and (B) Cyclic voltammogram with the corresponding ECL-voltage curve for $0.13 \mathrm{mM} \mathrm{tPDI} 2 \mathrm{~N}$-hex in benzene and acetonitrile (1:1 volume ratio) solution with $0.1 \mathrm{M}$ TBAP as the supporting electrolyte.

A)

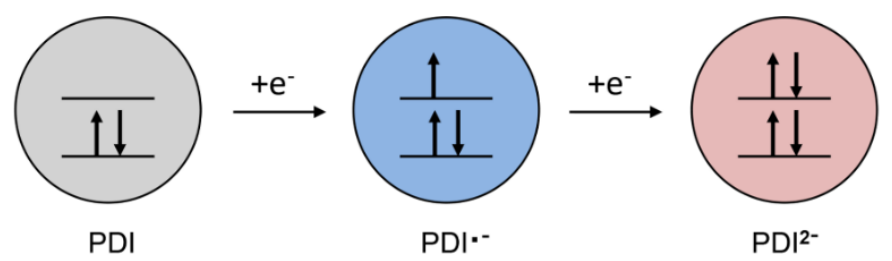

B)

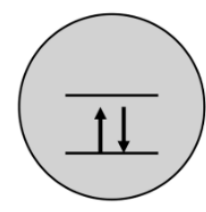

PDI

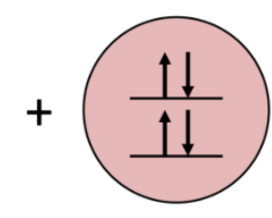

$\mathrm{PDI}^{2-}$
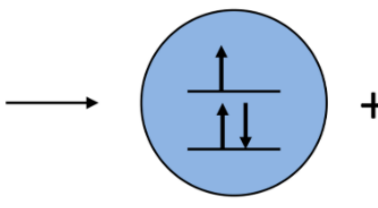

$\mathrm{PDI}$ *- $^{-12}$

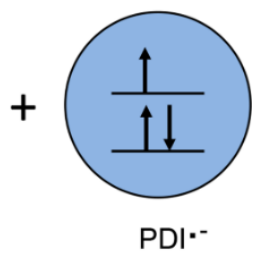

C)

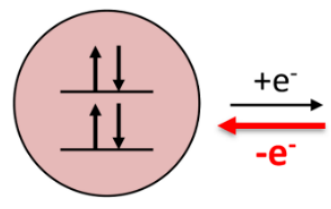

$\mathrm{PDI}^{2-}$

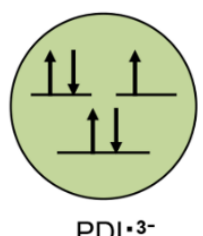

$\mathrm{PDI} \cdot 3^{-}$

Scheme S2. Reaction mechanisms in annihilation ECL pathways (PDI represents $\mathrm{PDI}_{2} \mathrm{~N}-\mathrm{hex}$ ): (A)

Two-step reductions. (B) Reaction between neutral PDI and PDI dianion. (C) The third reduction and its reverse reaction. 


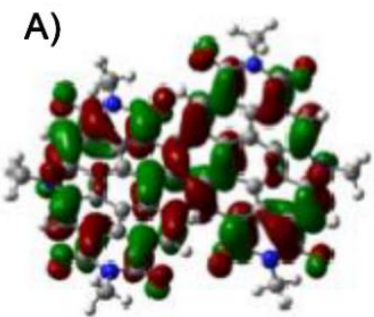

$-3.29 \mathrm{eV}$

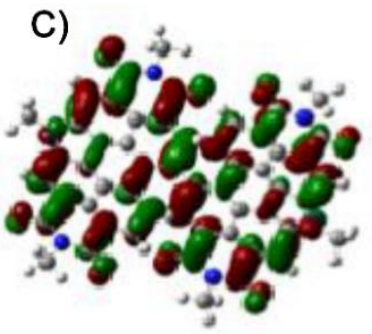

$-1.64 \mathrm{eV}$

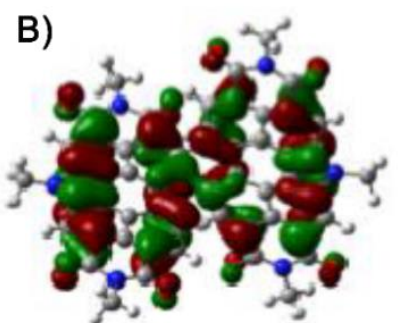

$-5.95 \mathrm{eV}$

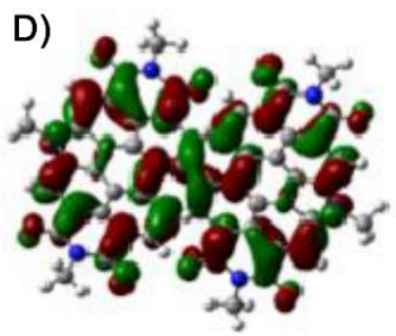

$0.77 \mathrm{eV}$

E)

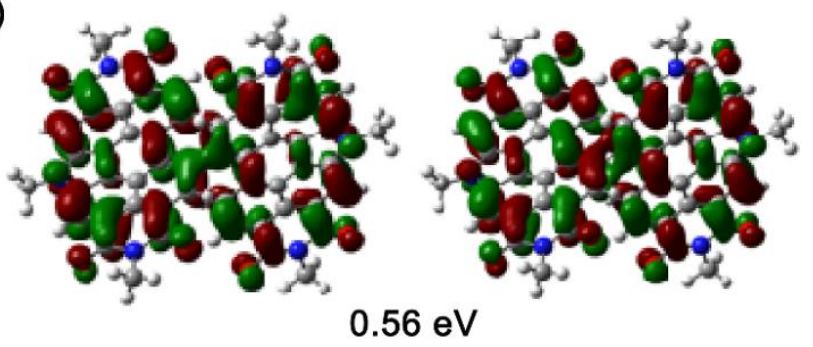

Figure S2. Frontier molecular orbitals and their calculated electronic energy levels: (A) LUMO of neutral tPDI ${ }_{2} \mathrm{~N}$-hex. (B) HOMO of neutral $\mathrm{PPDI}_{2} \mathrm{~N}$-hex. (C) SOMO of $\mathrm{PPDI}_{2} \mathrm{~N}$-hex radical anion. (D) HOMO of tPDI ${ }_{2} \mathrm{~N}$-hex singlet dianion. (E) SOMO of $\mathrm{tPDI}_{2} \mathrm{~N}$-hex triplet dianion (two orbitals are degenerated). 

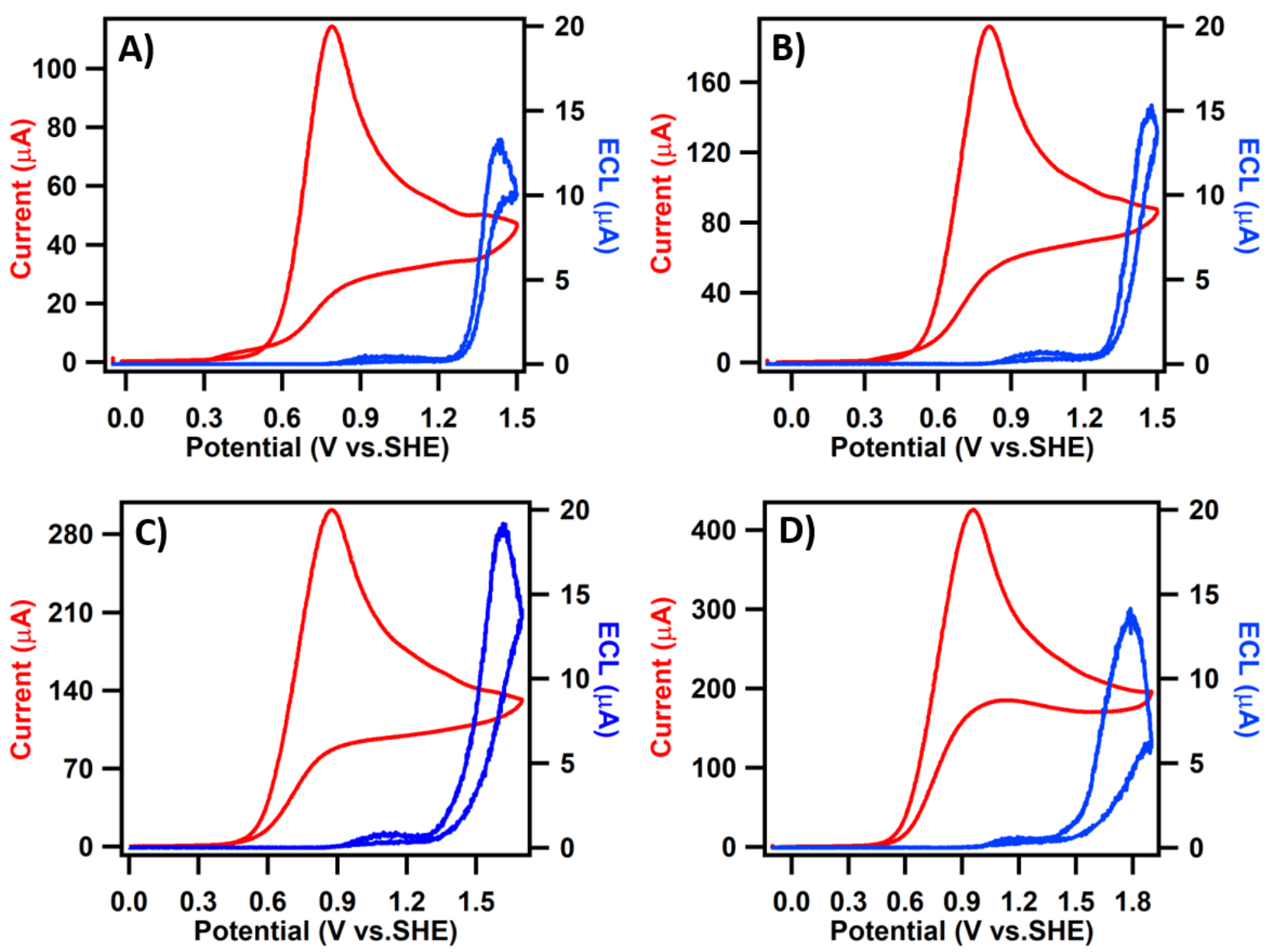

Figure S3. Cyclic voltammogram with the corresponding ECL voltage curve of $0.13 \mathrm{mM}$ tPDI ${ }_{2} \mathrm{~N}-\mathrm{hex}$ in the presence of TPrA at a concentration of (A) $5 \mathrm{mM}$ (B) $10 \mathrm{mM}$ (C) $20 \mathrm{mM}$ (D) $30 \mathrm{mM}$. All above were in benzene and acetonitrile (1:1 volume ratio) solution with $0.1 \mathrm{M}$ TBAP as the supporting electrolyte, at a scan rate of $0.1 \mathrm{~V} / \mathrm{s}$. 


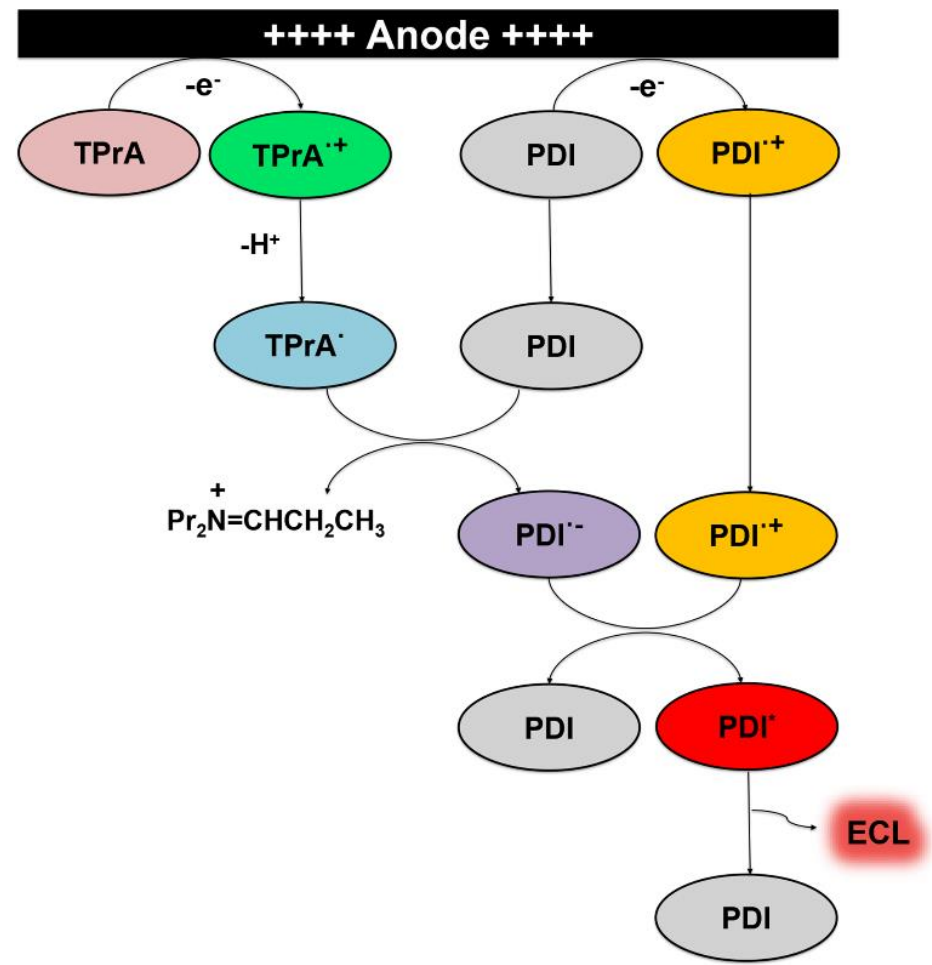

Figure S4. Mechanism 3 of coreactant ECL route with TPrA. 

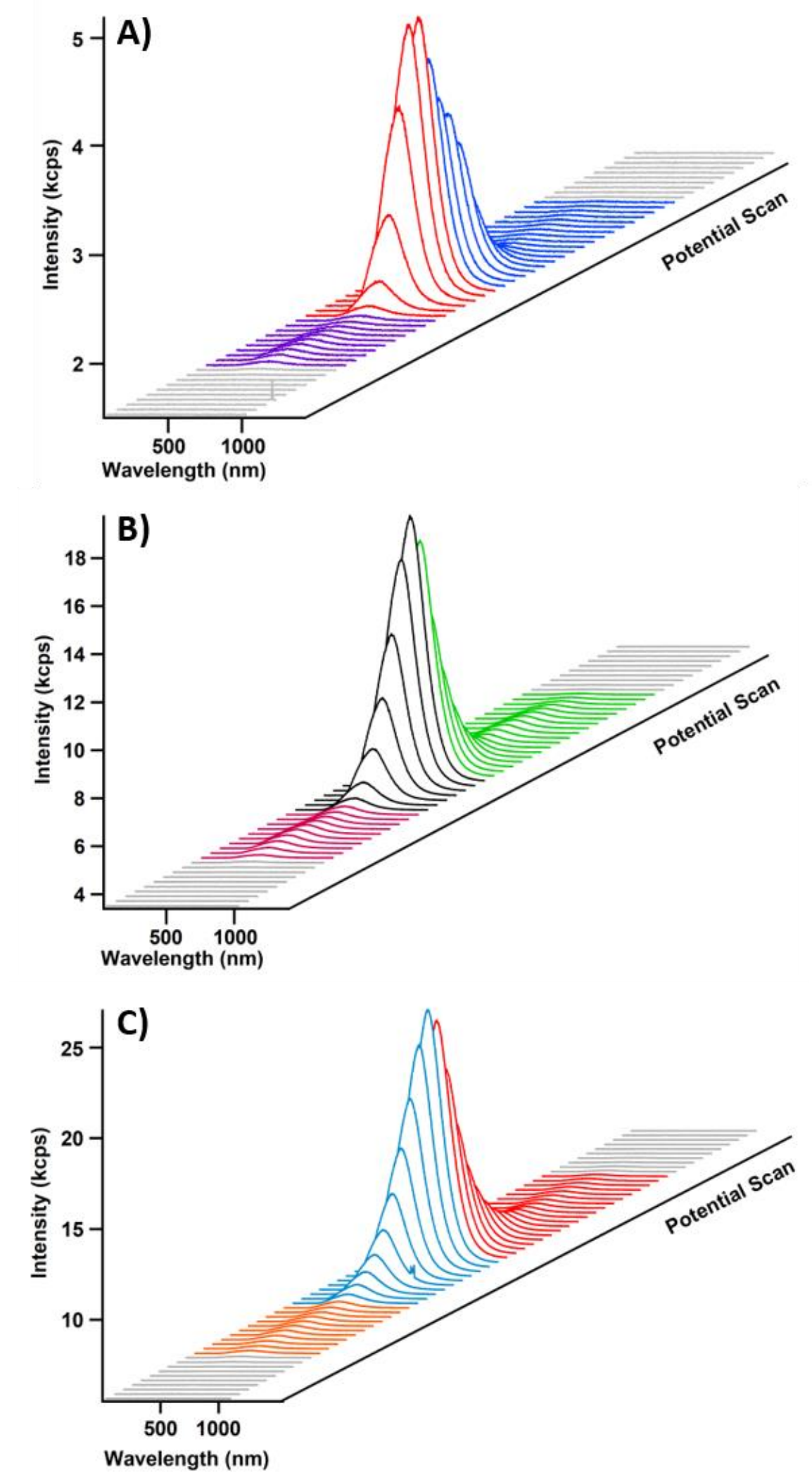

Figure S5. Spooling ECL spectra of $0.13 \mathrm{mM} \mathrm{tPDI}_{2} \mathrm{~N}$-hex in the presence of (A) $5 \mathrm{mM}$, (B) $10 \mathrm{mM}$ and (C) $30 \mathrm{mM}$ TPrA. 


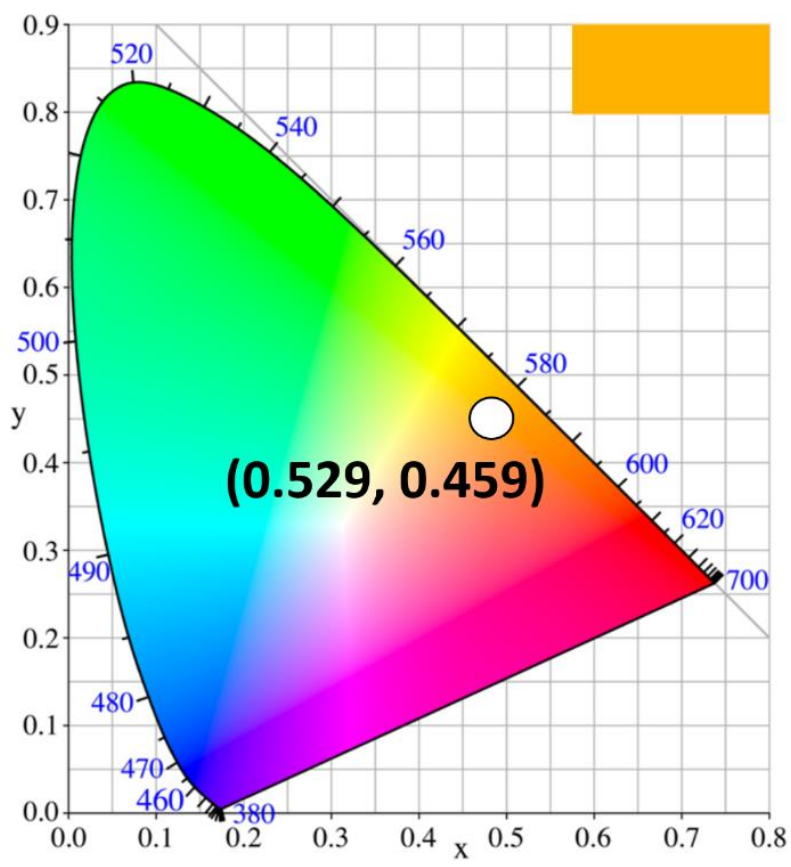

Figure S6. CIE coordinate diagram from an ECL spectrum in Figure 3.

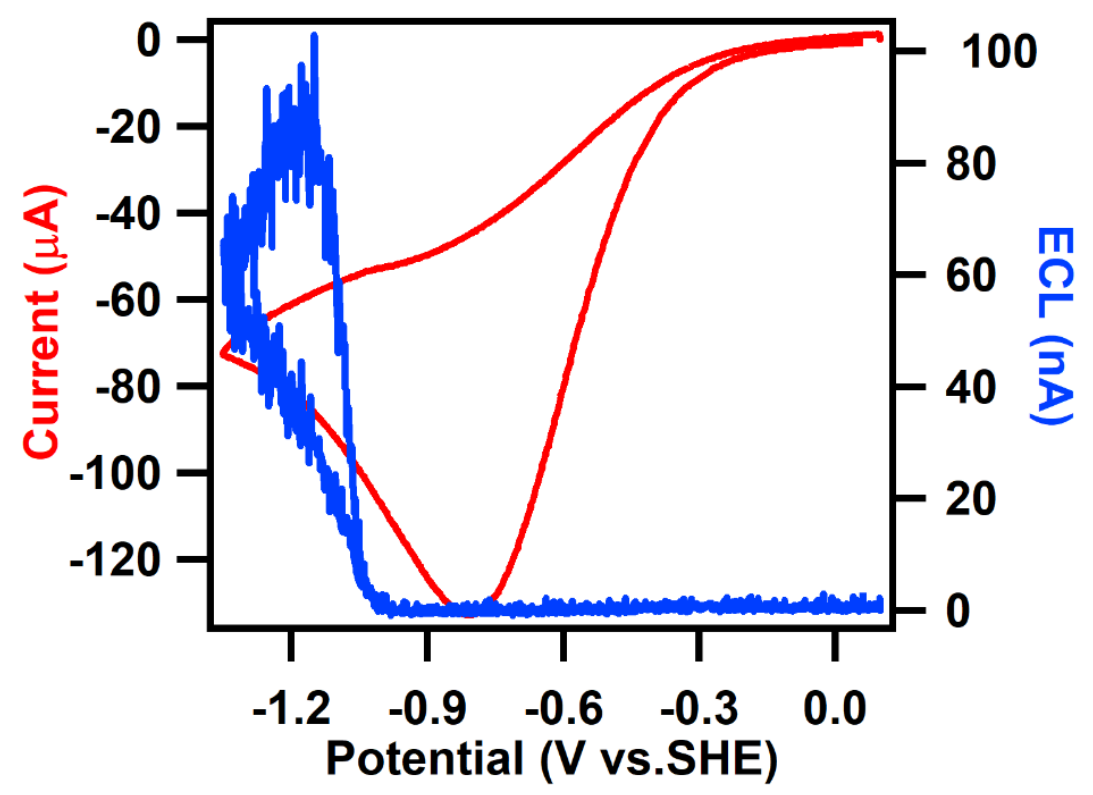

Figure S7. Cyclic voltammogram with the corresponding ECL-voltage curve of $0.13 \mathrm{mM}$ tPDI ${ }_{2} \mathrm{~N}-h$ ex in the presence of $5 \mathrm{mM} \mathrm{BPO}$. 


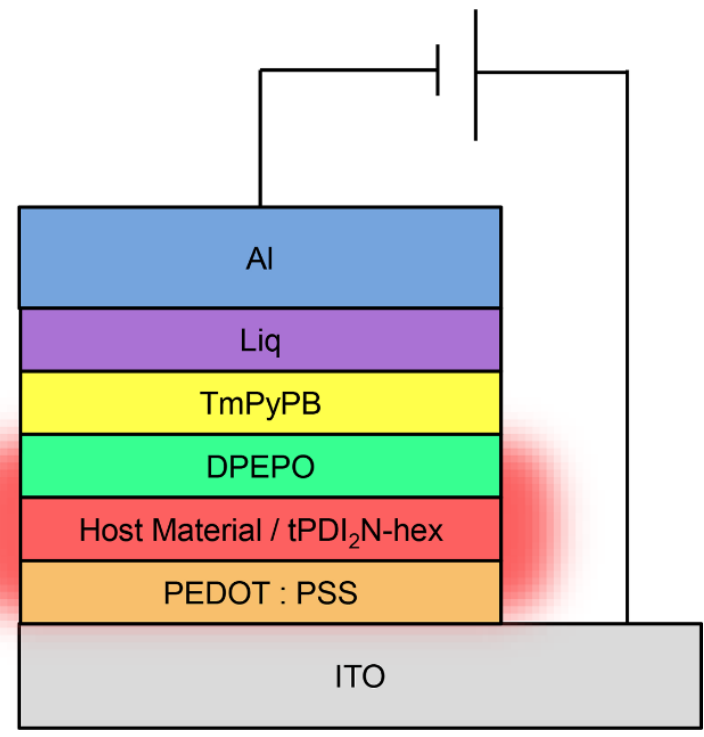

Figure S8. Layered structure of OLED devices fabricated with $\mathrm{tPDI}_{2} \mathrm{~N}$-hex

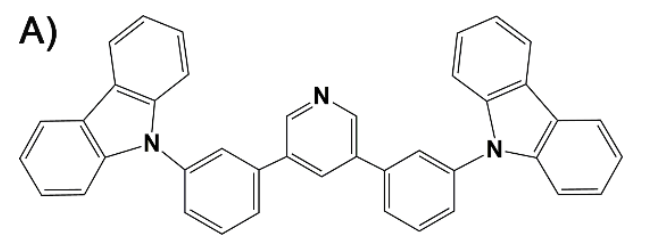<smiles>Cc1cccc(N(c2ccccc2)c2ccccc2)c1</smiles><smiles>Cc1cccc(N(c2ccccc2)c2ccccc2)c1</smiles><smiles>c1cc(-n2c3ccccc3c3ccccc32)cc(-n2c3ccccc3c3ccccc32)c1</smiles>

B)
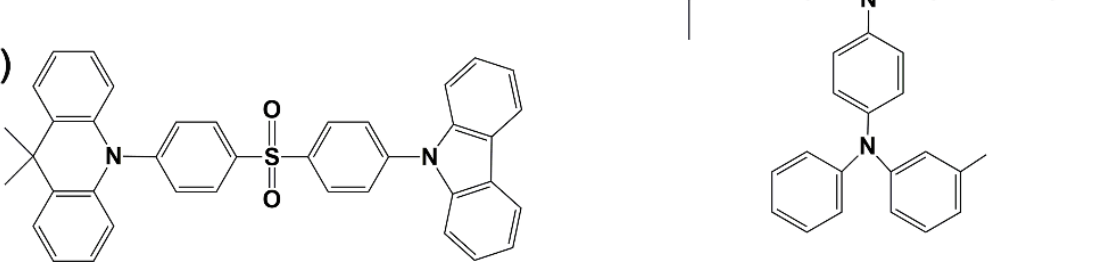

Figure S9. Molecular structures of the host materials employed in the EML: (A) 35DCzPPy. (B) CzAcSF. (C) m-MTDATA. (D) mCP. 
Table S1. EL performance of OLEDs fabricated with PDI derivatives.

\begin{tabular}{|c|c|c|c|}
\hline PDI Derivatives & $E Q E_{\max }(\%)$ & $L_{\max }\left(\mathrm{cd} / \mathrm{m}^{2}\right)$ & Reference \\
\hline $\mathrm{tPDI}_{2} \mathrm{~N}-\mathrm{EH}$ & 0.057 & 435 & $\begin{array}{l}\text { J. Mater. Chem. C, 2020, 8, 2314- } \\
2319\end{array}$ \\
\hline PDI-1 & 0.238 & 141 & \multirow{2}{*}{ RSC Adv., 2016, 6, 61175-61179 } \\
\hline PDI-2 & 0.638 & 46 & \\
\hline PDI-1BN & 1.57 & 1100 & J. Org. Chem. 2015, 80, 196-203 \\
\hline STPH & 3.97 & 1980 & \multirow{6}{*}{ Sci. Bull., 2018, 63, 108-116 } \\
\hline DTPH & 4.30 & 1298 & \\
\hline STRPH & 4.93 & 1948 & \\
\hline DTRPH & 3.52 & 1396 & \\
\hline STTPE & 0.50 & 728 & \\
\hline DTTPE & 0.49 & 363 & \\
\hline
\end{tabular}
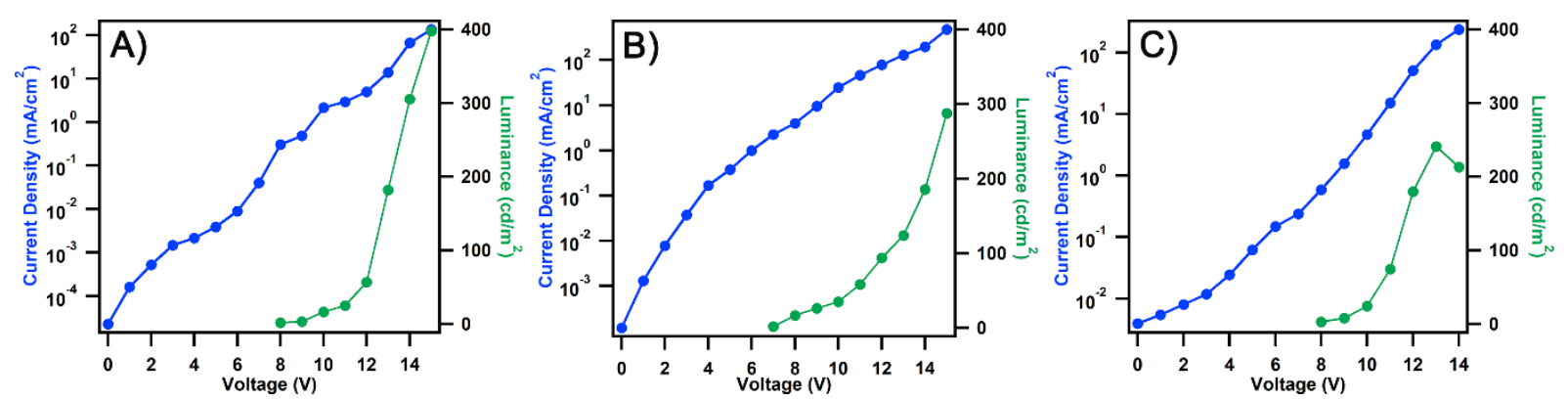

Figure S10. J-V curves (blue) and L-U curves (green) of (A) device 2 (B) device 3 (C) device 4. 

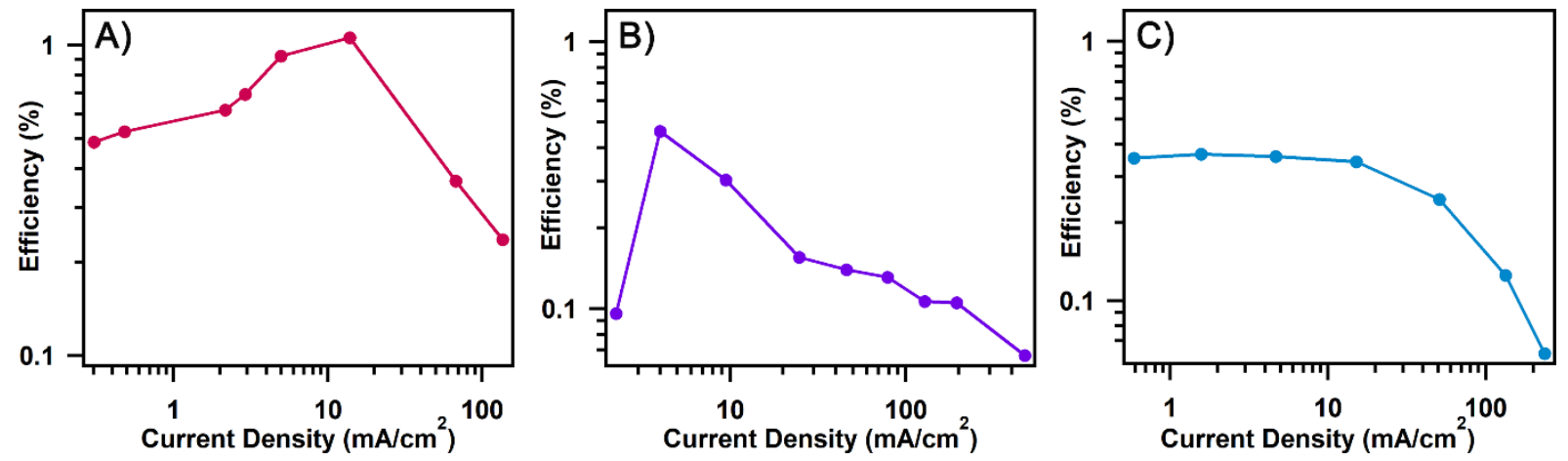

Figure S11. EQE-current density curves of (A) device 2 (B) device 3, and (C) device 4.
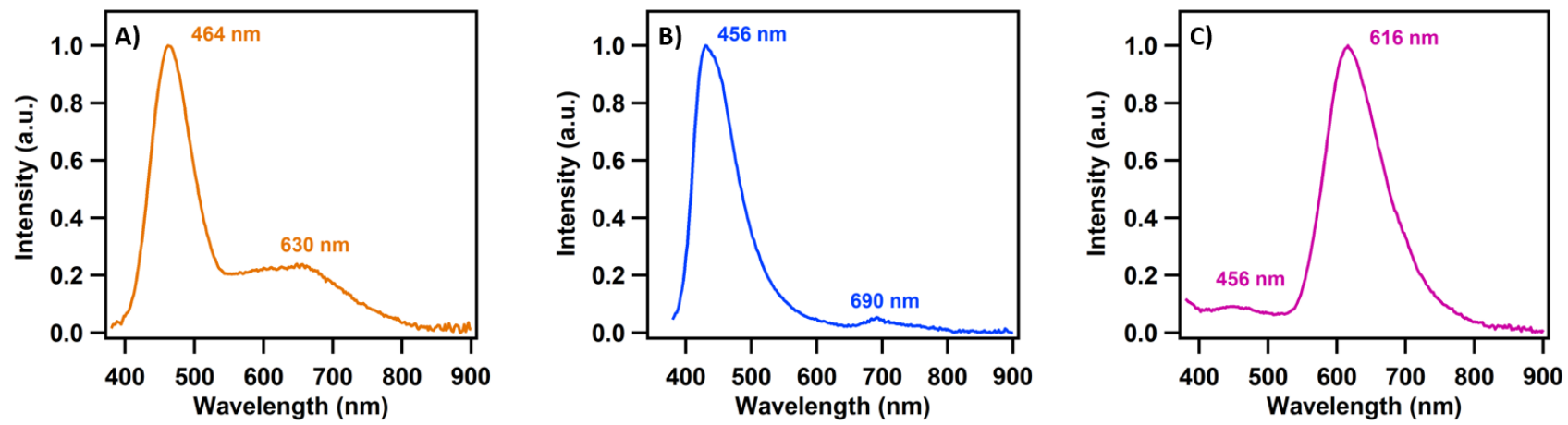

Figure S12. EL spectra of (A) device 2 (B) device 3, and (C) device 4.

\section{Chemicals and materials}

Benzene $(99.8 \%)$ and acetonitrile $(\mathrm{MeCN}, 99.8 \%)$ are anhydrous and stored in Sure/Seal ${ }^{\mathrm{TM}}$ bottles separately which were immediately transferred into a $\mathrm{N}_{2}$ filled glove box. The benzene, acetonitrile, tris(2,2'-bipyridyl)-ruthenium (II) hexafluorophosphate $\left[\mathrm{Ru}(\mathrm{bpy})_{3}\left(\mathrm{PF}_{6}\right)_{2}, 98 \%\right]$, tri- $n$-propylamine (TPrA, $\geq 98 \%$ ), and ferrocene (Fc, 98\%) were all obtained from Sigma-Aldrich (Mississauga, ON, Canada). Tetra- $n$-butylammonium perchlorate (TBAP, electrochemical grade) which acted as the supporting electrolyte in ECL test was purchased from Alfa Aesar (Ward Hill, MA). The TPrA and BPO were stored at $4{ }^{\circ} \mathrm{C}$ in a refrigerator while all the other chemicals were stored at room temperature. All the other organic materials except $\mathrm{PPDI}_{2} \mathrm{~N}$-hex used in OLED experiment were purchased from Lumtec, Inc. 
All other chemicals for OLED fabrication are from Adamas Reagent Ltd. (Shanghai, China), Energy Chemiacl Co. Ltd. (South Korea), Merck KGaA (Germany), Heowns Co. Ltd. (Tianjin, China), J\&K Scientific Ltd.(Beijing, China) and Luminescence Technology Corp. (Hsin Chu City, Taiwan).

\section{ECL Efficiency}

ECL efficiency is defined as the number of photons generated by the number of charges injected. It could be calculated relative to a commercialized ECL luminophore $\mathrm{Ru}(\mathrm{bpy})_{3}\left(\mathrm{PF}_{6}\right)_{2}$ by taking its efficiency as $100 \%$ under the same condition using the equation S1 as below:

$\Phi_{x}=\left(\frac{\int_{a}^{b} E C L d t}{\int_{a}^{b} \text { Current } d t}\right) /\left(\frac{\int_{a}^{b} E C L d t}{\int_{a}^{b} \text { Current } d t}\right)_{s t} \times 100 \%$

In this equation, $x$ represents the studied sample $\mathrm{tPDI}_{2} \mathrm{~N}$-hex while st represents the standard $\mathrm{Ru}(\mathrm{bpy})_{3}\left(\mathrm{PF}_{6}\right)_{2}$. The integration of ECL intensity and current versus time indicates the photons generated and charges injected in the system, respectively.

\section{Abbreviations}

PDI, perylene diimide; ECL, electrochemiluminescence; TPrA, tri- $n$-propylamine; OLED, organic lightemitting diode; GQDs, graphene quantum dots; ACQ, aggregation-caused quenching; CL, chemiluminescence; EL, electroluminescence; CVs, cyclic voltammograms; TBAP, tetra-nbutylammonium perchlorate; DPVs, differential pulse voltammograms; DFT, density functional theory; HOMO, highest-occupied molecular orbital; MO, molecular orbital; LUMO, lowest-unoccupied molecular orbital; SOMO, singly-occupied molecular orbital; PL, photoluminescence; ITO, indium tin oxide; PEDOT:PSS, poly(3,4-ethylenedioxythiophene)-doped poly(styrene sulfonate); 35DCzPPy, 3,5bis(3-(carbazol-9-yl)phenyl)pyridine; DPEPO, bis[2-(diphenylphosphino) phenyl] ether oxide; TmPyPB, 1,3,5-tri(m-pyrid-3-yl-phenyl)benzene; Liq, 8-hydroxyquinolinolato-lithium; EML, emitting layer; CzAcSF, 10-(4-((4-(9H-carbazol-9-yl)-phenyl)-sulfonyl)phenyl)-9,9-dimethyl-9,10-dihydroacridine; MTDATA, 4,4',4"'-Tris[phenyl(m-tolyl)-amino]triphenylamine; mCP, 1,3-Bis(N-carbazolyl)benzene; EQE, external quantum efficiency; CIE, commission internationale de I'Echairage. 